\title{
Non-visual differences between colour morphs of the polymorphic snail Arianta arbustorum
}

\author{
A. H. Abdel-Rehim*, \\ S. E. R. Bailey and \\ L. M. Cook
}

Department of Zoology, University of Manchester, Manchester M13 9PL, England.

\begin{abstract}
Brown shelled morphs of Arianta arbustorum are more frequent in shaded woodland than in open, sunnier habitats. This is thought to be the result of selective visual predation (Parkin, 1971). Yellow shelled morphs have a higher metabolic rate than browns, especially at high temperatures, and remain more exposed to sunlight. These non-visual differences in metabolism and behaviour will offset differences in radiant heat gain which result from the two shell colours in open habitats. Differences in heat gain will seldom occur in shaded habitats. The non-visual differences therefore appear to adjust for differences in energy gain caused by shell colour, rather than to act as component forces generating the polymorphism. They therefore do not have a balancing effect.
\end{abstract}

\section{INTRODUCTION}

The causes of polymorphisms in land molluscs continue to be discussed. Some authors argue that selection is relatively unimportant. For example, the large scale patterns of isozyme frequencies in Cepaea nemoralis studied by Ochman et al. (1983) are interpreted as due to accumulation of genetic differences in small populations through adaptive response, genetic drift or both, followed by expansion and secondary contact. Moreover, because no relationships of allele frequencies with environmental variation have been found, it seems unlikely that adaptation to local environments has been involved (Selander and Ochman, 1983). Agreement has not been reached on the factors likely to maintain visual polymorphisms in this and other species (e.g., Jones, Leith and Rawlings, 1977). If selection is claimed to be involved it is always possible to argue that the fitness differences are due to otherwise undetected loci linked to those controlling the visual phenotypes. In that case it would be impossible to arrive at an explanation related to the properties of the morphs which are

\footnotetext{
* Present address: Department of Zoology, Al-Azhar University, Nasr City, Cairo, Egypt.
}

scored. On the other hand, visual polymorphisms in a wide range of genera in a variety of families are correlated with living in heterogeneous foliage habitats (Clarke, Arthur, Horsley and Parkin, 1978), while species in other types of habitat are more likely to be monomorphic. This suggests that the effects on fitness act through the properties of the visual phenotypes themselves.

An explanation depending only on visual appearance is that predation operates in a frequency-dependent manner to conserve variety (see Clarke et al., 1978). This would be most likely to be effective when the morphs are very distinct from each other in appearance, as in Cepaea. However, differences in colour also affect the amount of energy of certain wavelengths received by the animal within the shell, and it is possible that polymorphisms may arise as a result of a balance of crypsis and of the differences in net energy gain which are a necessary concomittant of the visual differences. The experiments discussed here were undertaken to look for possible balancing interactions between visual and non-visual properties of a pair of distinct visual morphs. The experimental design and full details of the outcome are given elsewhere (Abdel-Rehim, 1983a, $b$, $1984 a, b)$. 


\section{MATERIALS AND METHODS}

The snail Arianta arbustorum is polymorphic for shell colour over much of its range. The morphs have a pigmented shell, usually with a single band, or an unpigmented shell, usually bandless or hyalozonate banded. Coupled with the yellow peristracum they appear brown or yellow (Cook and King, 1966). It is known that browns are at a higher frequency in woodland than in open habitats in a given area, and there is evidence of selective predation (Parkin, 1971). Yellows are on average at higher frequencies in humid regions than in dry ones, indicating that relative fitness is correlated in some way with climate (Parkin, 1972, Cain, Cameron and Parkin, 1969). The species is therefore a good one in which to examine the relation between the visual and the non-visual attributes of the morphs as a step towards building up a picture of how the polymorphism is maintained.

The material was collected at intervals over five years from a single location in Miller's Dale, Derbyshire (National Grid Reference SK 133728). We do not know whether the results are applicable to other populations, but the procedure used minimises the possibility of effects arising from inter-population variation. Many studies of polymorphic snails have been criticised on grounds of weakness arising from this source (Clarke et al., 1978). A series of five independent factorial experiments was carried out, in which (a) nocturnal activity, (b) food consumption, (c) assimilation efficiency, (d) metabolic rate and (e) mortality were measured in juveniles and adults of the two phenotypes at a range of adaptation temperatures, periods of acclimatisation and experimental temperatures and humidities.
Land snails have relatively poor physiological homeostatic ability, and respond readily to change in physical conditions (Steigen, 1979). Differences in response between the morphs are likely to be small in comparison with the overall changes. The intention was therefore to look for interactions between morph and one or other of the physical factors which were varied. Significant interactions would indicate that the morphs respond differently to the change and thus differ in adaptation ability. Higher order interactions may also be meaningful, but they are difficult to interpret, and are therefore not discussed.

\section{RESULTS}

The results are shown in table 1, which gives the significance of the main effects and the first order interactions with colour in the five experiments. A factor which was not tested is indicated by a dash.

There is a main effect of shell colour only with respect to metabolic rate, yellow individuals having a very significantly higher metabolic rate than browns. There is also a significant interaction of colour and environmental temperature. Temperature was varied from $5^{\circ} \mathrm{C}$ to $30^{\circ} \mathrm{C}$ in steps of $5^{\circ} \mathrm{C}$. There is a negligible difference in metabolic rate between colours at 5 and $10^{\circ} \mathrm{C}$, but a progressive divergence at higher temperatures (table 2(a)). Yellow snails also eat less food than browns at $5^{\circ} \mathrm{C}$ and more at $20^{\circ} \mathrm{C}$. Although the pairwise comparisons at each temperature are in no case significant (table 2(b)), the result is a significant interaction between morph and temperature with respect to food consumption $(P<0 \cdot 04)$. With regard to assimilation efficiency there is an interac-

Table 1 Summary of live factorial experiments, showing the significance of the effect of varying the factor at the left on response as measured by the variable at the top

\begin{tabular}{|c|c|c|c|c|c|}
\hline Source of variation & $\begin{array}{l}\text { Nocturnal } \\
\text { activity }\end{array}$ & $\begin{array}{l}\text { Food } \\
\text { consumption }\end{array}$ & $\begin{array}{l}\text { riable measured } \\
\text { Assimilation } \\
\text { efficiency }\end{array}$ & $\begin{array}{l}\text { Metabolic } \\
\text { rate }\end{array}$ & $\begin{array}{l}\text { Mortality } \\
\text { rate }\end{array}$ \\
\hline Relative humidity $(H)$ & $\therefore 0.001$ & $\ll 0 \cdot()() 1$ & $\ll 0.001$ & $\ll 0 \cdot 001$ & n.s. \\
\hline $\operatorname{Agc}(A)$ & n.s. & $\ll 0 \cdot 001$ & n.s. & - & $\ll 0 \cdot 00)$ \\
\hline Environmental temperature $(E)$ & $\ldots$ & - & - & $\therefore 0 \cdot 001$ & $\ll 0 \cdot 001$ \\
\hline$C \times T$ & n.s. & $\therefore 0 \cdot 04$ & n.s. & n.s. & n.s. \\
\hline$C \times H$ & n.s. & n.s. & n.s. & n.s. & n.s. \\
\hline$C \times A$ & n.s. & n.s. & $\therefore 0 \cdot 003$ & - & - \\
\hline$C \times E$ & - & - & - & $\ll 0.001$ & n.s. \\
\hline$C \times W$ & n.s. & n.s. & n.s. & - & n.s. \\
\hline
\end{tabular}


tion between stage of development and morph $(P<0.003)$. This is because yellow adults are less efficient than browns, while no difference was apparent between the juveniles (table 2(c)).

Table 2 Comparisons between morphs for conditions which produced significant interactions. Values of Student's $t$ are given, calculated using the error mean squares from the analyses of variance. Positive values indicate that yellows achieved a higher level than browns for the variable measured. The 5 per cent significance levels are $2 \cdot 11$ for (a), 2.00 for (b) and 1.99 for (c)

(a) Metabolic rate

\begin{tabular}{lrrr}
$\begin{array}{l}\text { Environmental } \\
\text { temperature } \\
\left({ }^{\circ} \mathrm{C}\right)\end{array}$ & \multicolumn{1}{c}{$\begin{array}{l}\text { mean oxygen consumption } \\
\left(\mu \mathrm{L} \mathrm{O}_{2} \mathrm{gm}^{-1} \mathrm{hr}^{-1}\right) \\
\text { Brown }\end{array}$} & \multicolumn{1}{c}{ Yellow } \\
\hline 5 & $0 \cdot 39$ & $50 \cdot 1$ & $54 \cdot 3$ \\
10 & $-0 \cdot 21$ & $52 \cdot 3$ & $50 \cdot 3$ \\
15 & $1 \cdot 27$ & $131 \cdot 3$ & $144 \cdot 8$ \\
20 & $2 \cdot 15$ & $100 \cdot 8$ & $123 \cdot 8$ \\
25 & $4 \cdot 35$ & $340 \cdot 9$ & $387 \cdot 4$ \\
30 & $6 \cdot 21$ & $180 \cdot 8$ & 247.3
\end{tabular}

(b) Food consumption

\begin{tabular}{llll}
$\begin{array}{l}\text { Adaptation } \\
\text { temperature } \\
\left({ }^{\circ} \mathrm{C}\right)\end{array}$ & $t$ & $\begin{array}{l}\text { mean food consumption } \\
\left(\mathrm{mg} \mathrm{gm}^{-1} \mathrm{day}^{-1}\right)\end{array}$ \\
\hline 5 & Brown & Yellow \\
14 & -1.90 & $17 \cdot 2$ & $15 \cdot 0$ \\
20 & -0.67 & $15 \cdot 7$ & 14.9 \\
& 1.67 & 16.6 & 18.6
\end{tabular}

(c) Assimilation efficiency

\begin{tabular}{|c|c|c|c|}
\hline \multirow[b]{2}{*}{ Stage } & \multirow[b]{2}{*}{$t$} & \multicolumn{2}{|c|}{ mean assimilation $(\%$} \\
\hline & & Brown & Yellow \\
\hline Juvenile & $0 \cdot 07$ & $96 \cdot 1$ & $98 \cdot 5$ \\
\hline Adult & $-1 \cdot 86$ & $97 \cdot 1$ & $96 \cdot 2$ \\
\hline
\end{tabular}

\section{CONCLUSION}

The two morphs perform very similarly, except that metabolic rate is higher in yellows than in browns. At higher temperatures yellows have a higher food consumption and a lower assimilation efficiency, while as temperature drops this effect is reduced and may reverse. Abdel-Rehim (1983b) has shown that in the wild, yellow snails from the area studied remained more exposed to light than browns. During three days observation in May they were more active than browns on the surface of vegetation in late afternoon. There is therefore a behavioural difference between the morphs with which the metabolic difference will interact. It is known that visual predation acts on this species, favouring dark colours in wooded areas and pale colours in open vegetation. The difference in colour also affects the absorption of radiant energy, which will be greater in browns than in yellows. The greater absorption by darker shells observed in Cepaea (Heath, 1975, Jones, 1973, Tilling, 1983) has also been inferred between brown and yellow in Arianta (Abdel-Rehim, 1983a). In the cooler closed habitats the received energy difference should be low, while in open habitats it will become greater. The experimental results do not involve consideration of radiant energy. They therefore indicate that in sunny conditions, where yellows should remain cooler than browns, there may be compensating metabolic differences which bring the metabolic energy balance nearer to that of the browns. Differences of $2-3^{\circ} \mathrm{C}$ in internal temperature have been recorded between brown and yellow shells of Cepea nemoralis at $20-25^{\circ} \mathrm{C}$ (Tilling, 1983). We do not have comparable figures for A. arbustorum, but if there is a similar temperature difference the yellows will have the same metabolic rate as the browns, or even a lower one (table 2(a)). The non-visual differences therefore appear to operate as an adjustment mechanism, making the different morphs similar to each other in metabolism, rather than as an essential component in the forces generating the polymorphism.

\section{REFERENCES}

ABIEL-REHIM, A. H. 1983a. Ph.D. Thesis, University of Manchester.

ABDEL-REHIM, A. H. 1983 b. Differences in habitat selection by different morphs of the snail Arianta arbustorum. Biol. J. Linn. Soc., 20, 185-193.

ABDEL-REHIM, A. H. 1984a. The effects of temperature and humidity on the nocturnal activity of different shell colour morphs of the Iand snail Arianta arbustorum. Biol. J. Linn. Soc., 20, 385-395.

ABDFL-REHIM, A. H. 1984 b. Metabolic adaptation in the polymorphic land snail Arianta arbustorum. J. moll. Stud. 50, 96-103.

CAIN, A. J., CAMERON, R. A. D. AND PARKIN, D. T. 1969. Ecology and variation of some helicid snails in northern Scotland. Proc. malac. Soc. Lond., 38, 269-299.

CLARKE, B. C., ARTHUR, W., HORSLEY, D. T. AND PARKIN, D. T. 1978. Genetic variation and natural selection in pulmonate molluscs. In Fretter, V. and Peake, J. (eds.) Pulmonates, vol. 2A. Academic Press, New York.

COOK, L. M. AND KING, J. M. B. 1966. Some data on the genetics of shell-character polymorphism in the snail Arianta arbustorum. Genetics, 53, 415-425.

HEATH, D. J. 1975. Colour, sunlight and internal temperature in the land snail Cepaea nemoralis (L.). Oecologia, Berlin, $19,29-38$.

JONES, J. S. 1973. Ecological genetics and natural selection in molluscs. Science, 182, 546-552.

JONES, J. S., LEITH, B. H. AND RAWLingS, P. 1977. Polymorphism in Cepaea: a problem with too many solutions? Ann. Rev. Ecol. Syst., 8, 109-143. 
A. H. ABDEL-REHIM, S. E. R. BAILEY AND L. M. COOK

O(HMAN, H., JONES, J. S. ANI) SELANI)IR, R. K. 1983. Molecular area effects in Cepaea. Proc. Natl. Acad. Sci. USA, 80, 4189-4193.

PARKIN, D. I. 1971. Visual selection in the land snail Arianta arbustorum. Heredity, 26, 35-47.

PARKIN, D. T. 1972. Climatic selection in the land snail Arianta arbustorum in Derbyshire, England. Heredity, 28, 49-56.

SELANDER, R. K. ANI) OCHMAN, H. 1983. The genetic structure of populations as illustrated by molluscs. In Isozymes:
Current Topics in Biological and Medical Research. 10, 93123.

STEIGI:N, A. L. 1979. Temperature effects on energy metabolism in banded and unbanded morphs of the snail Cepaea hortensis Müll. Oecologia, Berlin, 4I, 163-173.

TILLING, S. M. 1983. An experimental investigation of the behaviour and mortality of artificial and natural morphs of Cepaea nemoralis (L.). Biol. J. Linn. Soc., 19, 35-50. 